\title{
Influence of Blasting Vibration on Young Concrete Bridge: A Case Study of Yesanhe Super Large Bridge
}

\author{
Ming Chen, ${ }^{1,2}$ Jun Zhang, ${ }^{1,2}$ Wenbo Lu, ${ }^{1,2}$ Peng Yan, ${ }^{1,2}$ and Ke Deng ${ }^{1,2}$ \\ ${ }^{1}$ State Key Laboratory of Water Resources and Hydropower Engineering Science, Wuhan University, Wuhan, \\ Hubei 430072, China \\ ${ }^{2}$ Key Laboratory of Rock Mechanics in Hydraulic Structure Engineering of Ministry of Education, Wuhan University, \\ Wuhan, Hubei 430072, China \\ Correspondence should be addressed to Jun Zhang; 15997466258@163.com
}

Received 29 October 2016; Revised 22 January 2017; Accepted 6 February 2017; Published 9 March 2017

Academic Editor: Fiorenzo A. Fazzolari

Copyright (C) 2017 Ming Chen et al. This is an open access article distributed under the Creative Commons Attribution License, which permits unrestricted use, distribution, and reproduction in any medium, provided the original work is properly cited.

Influence of blasting vibration on young concrete structure is an important issue in the field of hydropower engineering, transportation, and so forth. Based on influence of blasting excavation on concrete pouring progress of box girder in nearby Yesanhe Super Large Bridge, which is located in Hubei Province of China, a method combining field test and numerical simulation is used to study influence of blasting vibration on young concrete super large bridge. The results show that blasting excavation of nearby Yesanhe Hydropower Station induced vibration response on Yesanhe Bridge and peak particle velocity (PPV) on the bridge was quite small under test conditions. Monitoring data and numerical simulation both indicate that PPV of box girder is 1 to 4 times larger than that of pier foundation; with the extension of bridge cantilever casting section, velocity amplification factors of different parts of the box girder have different changes and duration of vibration in vertical direction increases. Three days after concrete pouring, the impact of concrete ageing on PPV and damage distribution of the bridge is not obvious. When vibration velocity of pier foundation is within $2 \mathrm{~cm} / \mathrm{s}$, the maximum tensile and compressive stress of box girder concrete are less than the tensile and compressive strength of concrete, so that blasting vibration unlikely gives impact on the safety of bridge.

\section{Introduction}

Blasting is a common technique in hydraulic and hydroelectric engineering, highway and railway construction, mining, and other engineering fields. With mass infrastructure construction in China, mutual interference of blasting construction in time and space begins to appear. Harmful effects generated by blasting may threat the existing buildings (structures) nearby. So now we pay much more attention to blasting vibration which is the first harmful effect.

In the project of Shanghai-Chongqing expressway, blasting effect existed on the Yesanhe Super Large Bridge in construction. Cracks appeared on box girder of the bridge as blasting excavation of nearby Yesanhe Hydropower Station was going on. This phenomenon caused particular concern of all involved bridge construction unit and also resulted in nearly a month of downtime. During the downtime, engineers analyzed the causes, and blasting vibration was one of them. Influence of blasting vibration on young concrete bridge mainly comprised vibration response characteristics of bridge under blasting vibration load and the impact of blasting vibration on safety of young concrete.

Over the years, many scholars have studied the influence of blasting vibration on nearby buildings (structures) $[1,2]$ and put forward safety criterion such as vibration velocity and frequency [3, 4]. Li et al. [5] monitored the vibration of pier in Suancigou Bridge which is nearby Heidaigou open-cast mine and they applied ANSYS and LS-DYNA to numerical simulation about structural dynamic response. Huang et al. [6] researched distribution of PPV from bottom of pier to top of box girder in Xiamen-Zhangzhou sea-crossing bridge project. Bayraktar et al. $[7,8]$ evaluated safety effect on reinforced concrete expressway bridge, masonry construction, and stone arch bridge based on blasting vibration monitoring 


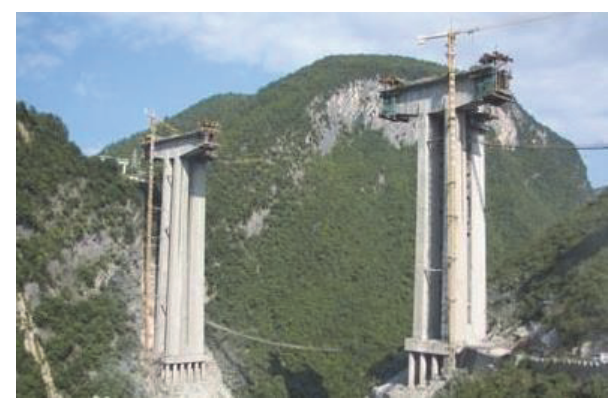

Figure 1: Yesanhe Super Large Bridge in construction.

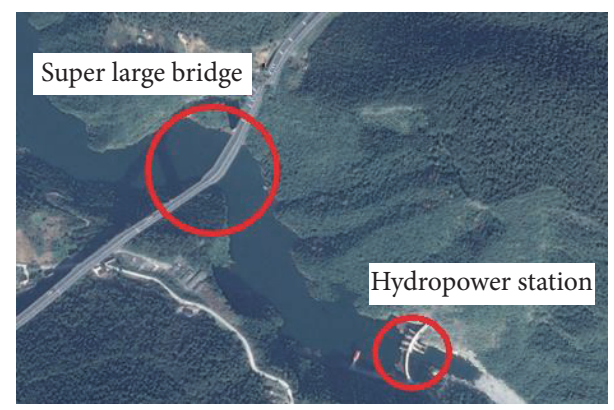

FIgure 2: Position of Yesanhe Super Large Bridge and Yesanhe Hydropower Station.

of quarry nearby the city center in Turkey's east black sea area. Dhakal and Pan [9] studied response characteristics of structures subjected to blasting-induced ground motion. Li et al. $[10,11]$ researched drift-controlled design of reinforced concrete frame structures under distant blast conditions.

Concrete is a major building material in bridge construction. Some researchers have analyzed the performance of young concrete and influence of blasting vibration on it. Huo and Wong [12] researched early properties of high performance concrete through experiments. Wang et al. [13] studied early-stage strength growth of concrete in outer freezing shaft wall by laboratory and field experiments. $\mathrm{He}$ found early strength of large volume concrete grew rapidly and strength at 3 and 7 days exceeded 70 and 90 percent of the final strength, respectively. Lu et al. [14] analyzed influence of blasting vibration on nearby structures and earlyage concrete in his introduction about safety regulations for blasting vibration in China. Chen et al. [15] researched blasting vibration control standards for new poured rock anchor beam in underground powerhouse. Yáñez [16] put forward several methods to control blasting vibration velocity of young concrete based on a hydroelectric engineering in Mexico.

As it can be seen from the above, many researchers have studied the dynamic response of bridge under blasting vibration, features of young concrete, and influence of blasting vibration on young concrete structures. However, the study about impact of blasting vibration on young concrete super large bridge under construction remained little. In this paper, we took Yesanhe Super Large Bridge as an

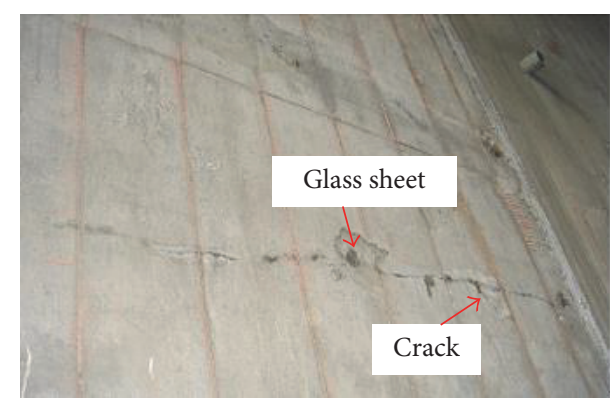

Figure 3: Cracks at the new poured box girder on 4\# pier before blasting test.

example and analyzed the monitoring vibration data of the bridge (mainly including pier foundation and box girder). Then we simulated dynamic response of the young concrete super large bridge under blasting seismic by LS-DYNA, a dynamic finite element program, to evaluate influence of blast vibration on the bridge.

\section{Field Monitoring for Dynamic Response of Yesanhe Super Large Bridge under Blasting Vibration}

2.1. General Situation of Yesanhe Super Large Bridge. Yesanhe Super Large Bridge is located in Shanghai-Chongqing expressway, at boundary of Enshi and Yichang in Hubei province. It stretches over Yesanhe Gorge, with 993 m length, and the main-span of the bridge was $200 \mathrm{~m}$ long. 3\# pier and $4 \#$ pier are on the river cliff. $3 \#$ pier foundation is about $80 \mathrm{~m}$ from bottom of the river and $120 \mathrm{~m}$ under the top of the gorge. There are a lot of fractures inside the mountain and the slope ratio of river cliff is greater than $80^{\circ}$. $4 \#$ pier foundation is about $100 \mathrm{~m}$ from bottom of the river and $80 \mathrm{~m}$ under the top of the gorge. The bridge in construction is shown in Figure 1. It is a cast-in-place prestressed reinforced concrete structure. Concrete pouring of the bridge and blasting excavation of Yesanhe Hydropower Station were conducted at the same time. The relative position of the bridge and hydropower station is shown in Figure 2. During the construction, as shown in Figure 3, cracks have appeared on the new poured box girder. Builders thought the cracks were possibly caused by blasting excavation, so they suspended construction and analyzed causes of that. As an important factor, blasting vibration was well researched.

2.2. Monitoring Plan of Blasting Vibration. Blasting test based on rock mass excavation for Yesanhe Hydropower Station was aimed to quantitatively evaluate the effect of blasting vibration on the box girder and pier foundation of bridge and put forward scientific and practical blasting vibration control measures. The tests were conducted 3 times, at intake slope, right abutment, and left abutment, respectively. Relative parameters were as follows: blast hole diameter was $90 \mathrm{~mm}$, blast hole depth was 8 22 m, single hole charge was 70-80 kg, and max explosive quantity of single shot was $141 \mathrm{~kg}$. The test 


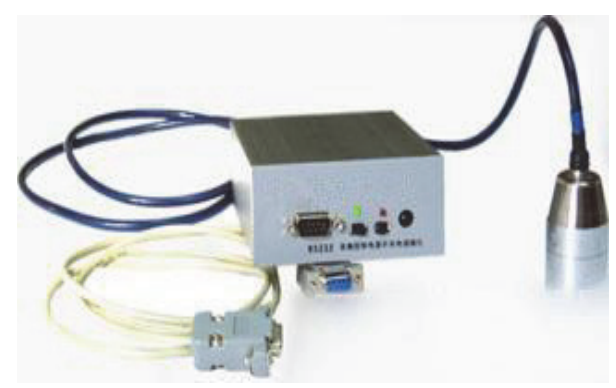

FIGURE 4: TOPBOX-508 vibration signal recording apparatus.

purpose was to get velocity response characteristic of 3\#, 4\# pier foundation and box girder.

2.2.1. Monitoring System. Theoretical analysis and engineering practice show that building destruction caused by blasting vibration has a good correlation with PPV. Scholars generally take PPV and corresponding main frequency as control parameters for blasting vibration safety. It is suggested to use PPV as the main index to evaluate blasting vibration safety of buildings in 〈Blasting Safety Regulations〉 (GB6722) of China. So we chose PPV and the main frequency as observation physical parameters of blasting vibration.

The field monitoring instruments system consists of vibration sensor, signal acquisition and recording equipment, and data processing system. Its core is TOPBOX-508 vibration signal recording apparatus, shown in Figure 4.

2.2.2. Monitoring Points Arrangement. Monitoring work was strictly followed the rules in 〈Blasting Safety Regulations〉 (GB6722) and 〈Blasting Safety Monitoring Regulations in Hydropower Engineering (DL-T 5333-2005). The tests and monitoring work were on the premise of safety of the bridge and related important facilities. In the test, monitoring points were set at $3 \#$, 4\# pier foundation and box girder, shown in Figure 5 . Each point collected blasting vibration velocity in vertical and horizontal radial (perpendicular to the bridge axis) direction. Casting sections and monitoring points on $4 \#$ pier are shown in Figure 6 as an example, 5\# and 6\# points are located at the pier foundation, $8 \#$ and $10 \#$ points are at edge of the box girder, and 9\# point is at center of the box girder.

2.3. Monitoring Results. Through analyzing monitoring results of pier foundation and box girder, we could find that vibration velocities of them were all not over $0.32 \mathrm{~cm} / \mathrm{s}$ and velocity of box girder was generally larger than that of pier foundation. PPV and the main frequency of pier foundation and box girder are shown in Table 1. Further analysis of the data has shown that vibration velocity of box girder was 1 to 4 times larger than that of pier foundation. It would be 2.33 times in horizontal radial direction and 2.08 times in vertical direction at the edge of the box girder if we used a weighted average of the velocity to evaluate amplification effect. Also, vibration velocity at center of the box girder was 1.54 times in horizontal radial direction and 1.53 times in vertical direction.
In order to monitor cracks extension caused by blasting, we pasted thin glass sheet across cracks on the girder, shown in Figure 3. After tests, we found that the glass sheet did not crack and existing cracks did not extend either. That is to say, blasting vibration was not a threat to the safety of the bridge as the field vibration velocity was small.

The cantilever would prolong with the box girder extending during the construction. Construction schedule of $3 \#$ and $4 \#$ pier was different, so we could compare vibration velocity amplification effect of box girder with different length. Through analyzing monitoring data of 3\#, 4\# pier and box girder, we find the relationship between vibration velocity and length of box girder is not clear enough. The points at the edge of $4 \#$ pier were $17 \mathrm{~m}$ from the center of the box girder and vibration velocity was 2.67 times than that of pier foundation in horizontal radial direction while it was 1.97 times than that of pier foundation in vertical direction. On $3 \#$ pier, it was $26 \mathrm{~m}$ from the center of the box girder but velocity was 1.83 times in horizontal radial direction and 2.73 times in vertical direction. The vertical vibration velocity magnification of $3 \#$ was larger than that of $4 \#$ while the horizontal radial magnification was smaller.

\section{Numerical Simulation of Blasting Vibration Response of the Super Large Bridge}

In the tests, due to low explosive quantity of single shot and long distance, vibration velocity of the super large bridge induced by blasting excavation of Yesanhe Hydropower Station was low, which means blasting vibration was not a threat to the safety of the bridge. To analyze influence of blasting excavation on the bridge with different explosive quantity of single shot, in this paper, we simulated blasting vibration response of young concrete super large bridge based on LS-DYNA. By adjusting the value of input vibration load, we can study the vibration response and safety of bridge under different blasting vibration load.

\subsection{Model and Parameter}

3.1.1. Model. We mainly simulate dynamic response of $4 \#$ pier (including foundation, pier, and poured box girder). The box girder was poured section by section and the length of each section from pier to middle of span differed at $3.5 \mathrm{~m}, 4 \mathrm{~m}$, and $4.5 \mathrm{~m}$. And the construction period of each section was 10 days. Four sections of $3.5 \mathrm{~m}$ were poured at both sides of the pier. Model which reflected the real situation (model I) was shown in Figure 7. Upper part of it is pier and box girder. The pier is $86.5 \mathrm{~m}$ high. The body applied double limb variable section rectangular hollow pier. The distance between limbs is $9 \mathrm{~m}$. Lower part is bedrock. Length, width, and height of the bedrock is $87 \mathrm{~m}, 61.5 \mathrm{~m}$, and $40 \mathrm{~m}$, respectively. This finite element model has 272014 elements, and element type is SOLID164. In order to ensure convergence of the mesh and avoid wave distortion [17], we need to control the mesh size. In our model, smallest mesh size is $0.38 \mathrm{~m}$, and the largest is $1.17 \mathrm{~m}$. Bottom and side of the bedrock are set to no reflection boundary. Meanwhile, we build model II whose box girder is 14.5 meters longer than model I based on construction 


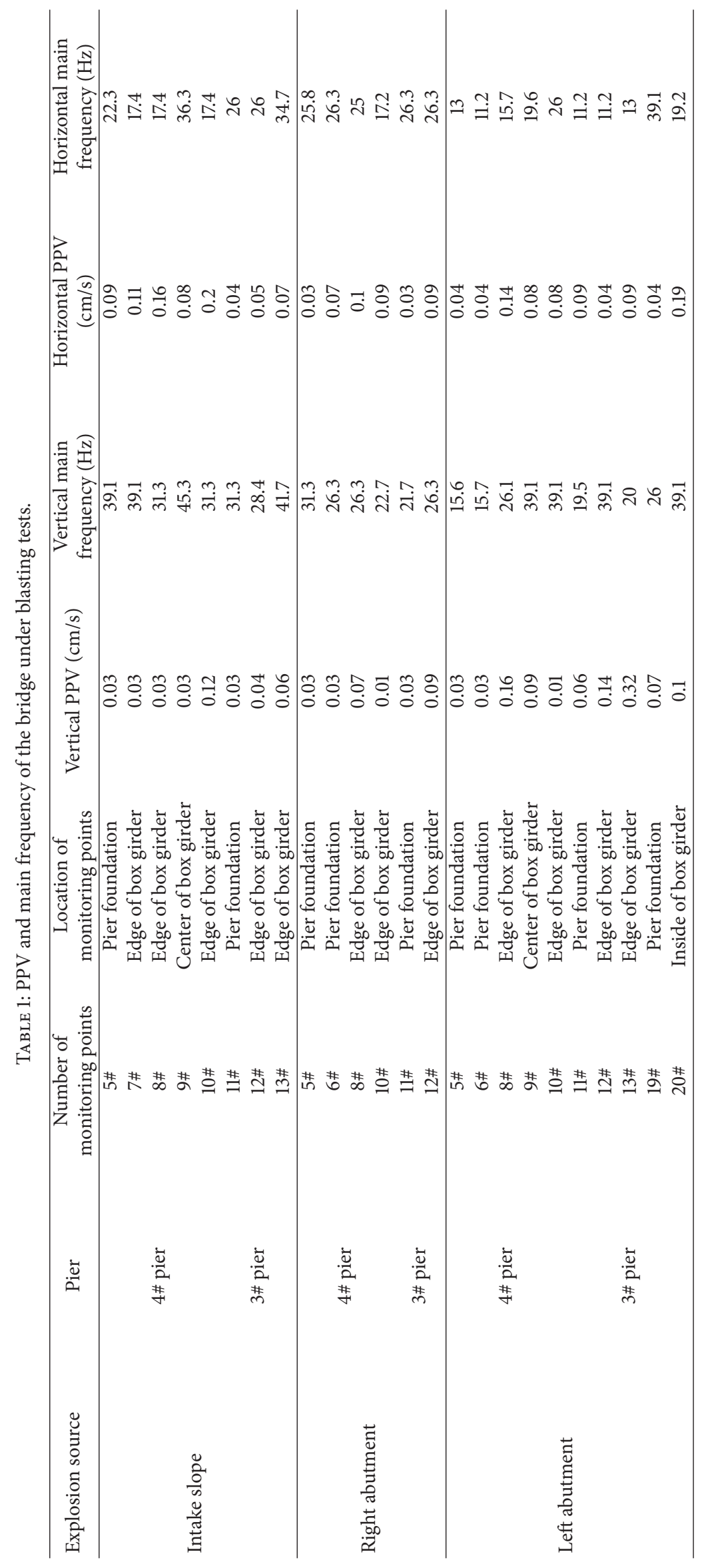




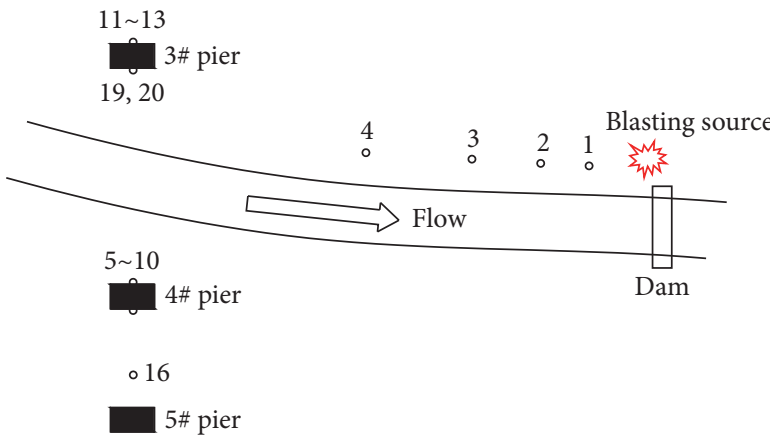

(a) Top view

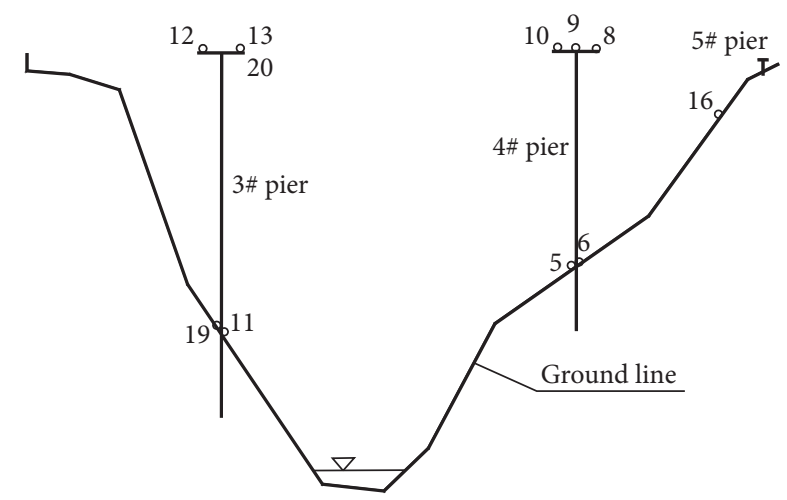

(b) Left view

FIGURE 5: Monitoring points in the blasting test at left abutment.

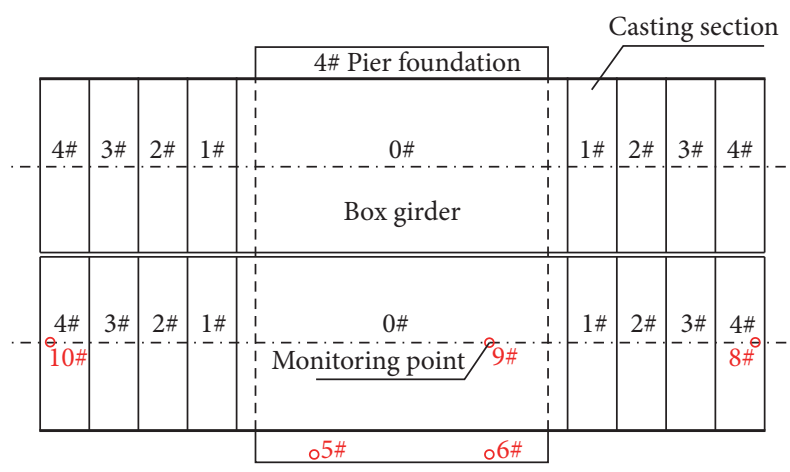

Figure 6: Casting sections and monitoring points on 4\# pier.

schedule to compare vibration response of different extended length of box girder.

3.1.2. Physical and Mechanical Parameters of Bedrock and Concrete. We thought the bedrock and concrete both meet bilinear elastic-plastic constitutive equations. The physical and mechanical parameters are very important to the vibration response of young concrete. According to measured data, we get parameters of bedrock which is shown in Table 2 .

To study the relationship between vibration response and concrete age, we set the latest poured concrete age at $3 \mathrm{~d}$ and $7 \mathrm{~d}$, respectively, to control age of each concrete section, as shown in Table 3. Strength of concrete grows slowly after 28 days, so we regard concrete whose age is more than $28 \mathrm{~d}$ as $28 \mathrm{~d}$.

The bridge was poured with C55 high strength concrete. Relationship between the compressive strength and age was different with ordinary concrete. How relative compressive strength changes with concrete age [18] in 28 days is shown in Figure 8.

The dynamic elasticity modulus can be calculated according to the experience formula (1):

$$
E_{d}=7.6 f_{\mathrm{cu}}^{0.33}+14
$$



FIGURE 7: Finite element model (model I).

where $E_{d}$ is dynamic elasticity modulus, $10^{3} \mathrm{MPa} ; f_{\mathrm{cu}}$ is compressive strength, $\mathrm{MPa}$.

We consider six kinds of concrete age during the simulation. The parameters are tangent modulus of the reinforced concrete $E_{d}^{\prime}=0.75 E_{d}$ and yield strength $\sigma_{s}=0.4 f_{\text {cu }}[19]$, density was $2500 \mathrm{~kg} / \mathrm{m}^{3}$, and Poisson's ratio was 0.2 . Physical and mechanical parameters of concrete in different ages are shown in Table 4. 
TABLE 2: Physical and mechanical parameters of bedrock.

\begin{tabular}{lccccc}
\hline $\begin{array}{l}\text { Elasticity } \\
\text { modulus/(GPa) }\end{array}$ & Density $/\left(\mathrm{kg} / \mathrm{m}^{3}\right)$ & Poisson's ratio & $\begin{array}{c}\text { Compressive } \\
\text { strength/(MPa) }\end{array}$ & $\begin{array}{c}\text { Tangent } \\
\text { modulus/(GPa })\end{array}$ & $\begin{array}{c}\text { Yield } \\
\text { strength/(MPa) }\end{array}$ \\
\hline 40 & 2650 & 0.22 & 41 & 30 & 16.4 \\
\hline
\end{tabular}

TABLE 3: Concrete age of each section (model I).

\begin{tabular}{llllll}
\hline Section & $0 \#$ & $1 \#$ & $2 \#$ & $3 \#$ & $4 \#$ \\
\hline \multirow{2}{*}{ Age/d } & 48 & 33 & 23 & 13 & 3 \\
& 52 & 37 & 27 & 17 & 7 \\
\hline
\end{tabular}

TABLE 4: Physical and mechanical parameters of concrete in different ages.

\begin{tabular}{lcccc}
\hline Ages/(d) & $\begin{array}{c}\text { Compressive } \\
\text { strength/(MPa) }\end{array}$ & $\begin{array}{c}\text { Elasticity } \\
\text { modulus/(GPa) }\end{array}$ & $\begin{array}{c}\text { Tangent } \\
\text { modulus/(GPa) }\end{array}$ & Yield \\
strength/(MPa)
\end{tabular}

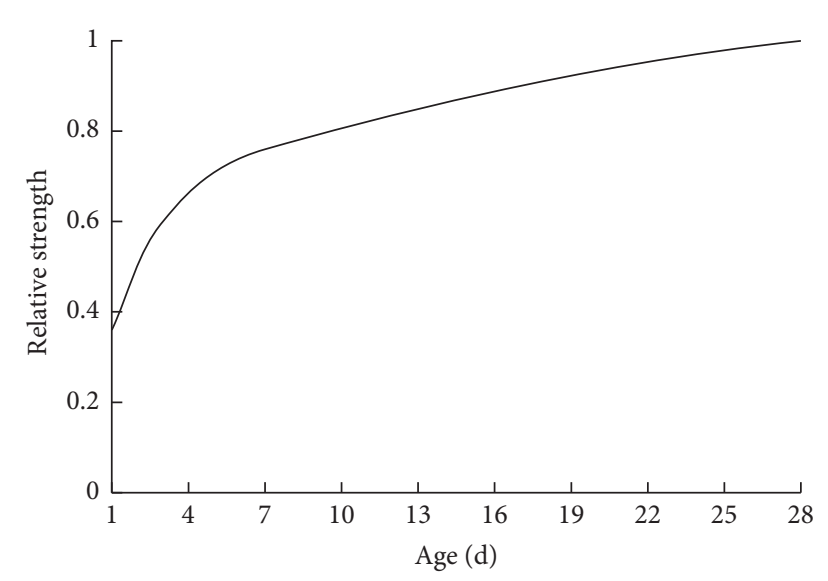

FIGURE 8: Relationship between relative compressive strength and age of C55 concrete

We take reinforced concrete as a single material here and adjust the equivalent damping to show the role of steel bar in structure's dynamic response [20]. In the numerical simulation, mass-damping is set to 1.75 and stiffness-damping is set to 0.0005 .

3.1.3. Blasting Vibration Load. In the test at left abutment, we got blasting vibration wave in vertical and horizontal radial direction (perpendicular to the bridge axis) at $4 \#$ pier foundation, and PPV was $0.03 \mathrm{~cm} / \mathrm{s}$, shown in Figure 9 .

We choose vibration velocity wave near the peak velocity as velocity load during the simulation, as shown in Figure 10.

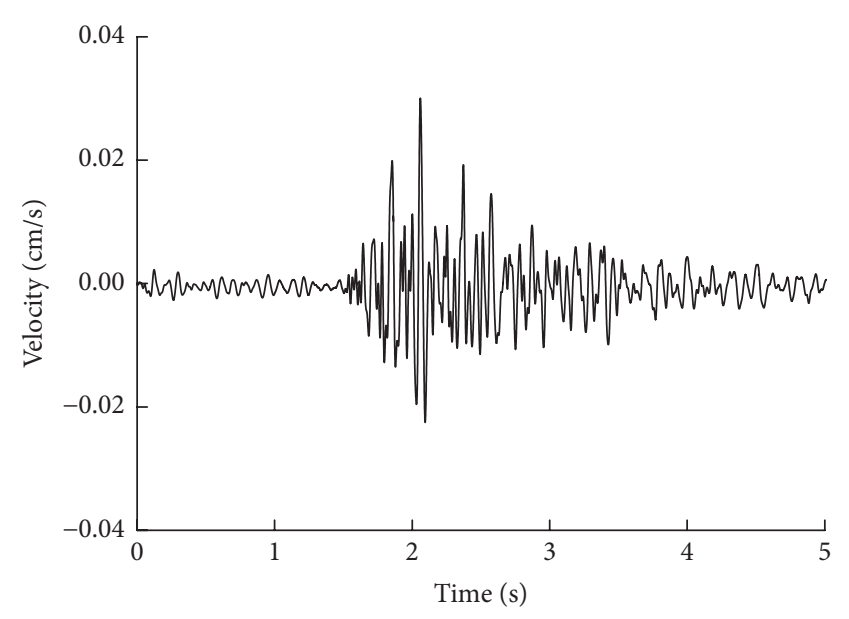

FIGURE 9: Curve of measured blasting vibration wave at $4 \#$ pier foundation.

In addition, we magnify peak velocity to $0.5 \mathrm{~cm} / \mathrm{s}$ and $2 \mathrm{~cm} / \mathrm{s}$ without changing other characteristics, so that we can study vibration response of the bridge when vibration velocity at pier foundation is much larger and put forward vibration safety criterion for the bridge under blasting vibration. The velocity load is applied on the side of bedrock, shown in Figure 7.

3.1.4. Simulation Conditions. Based on different combinations of model, concrete age, and load, we list the simulation conditions, shown in Table 5. 
TABLE 5: Simulation conditions.

\begin{tabular}{|c|c|c|c|}
\hline Serial number & Model & Age of latest poured section (d) & Peak of load $(\mathrm{cm} / \mathrm{s})$ \\
\hline 1 & \multirow{6}{*}{ Model 1} & \multirow{3}{*}{3} & 0.03 \\
\hline 2 & & & 0.50 \\
\hline 3 & & & 2.00 \\
\hline 4 & & \multirow{3}{*}{7} & 0.03 \\
\hline 5 & & & 0.50 \\
\hline 6 & & & 2.00 \\
\hline 7 & \multirow{6}{*}{ Model 2} & \multirow{4}{*}{3} & 0.03 \\
\hline 8 & & & 0.50 \\
\hline 9 & & & 2.00 \\
\hline 10 & & & 0.03 \\
\hline 11 & & \multirow[t]{2}{*}{7} & 0.50 \\
\hline 12 & & & 2.00 \\
\hline
\end{tabular}

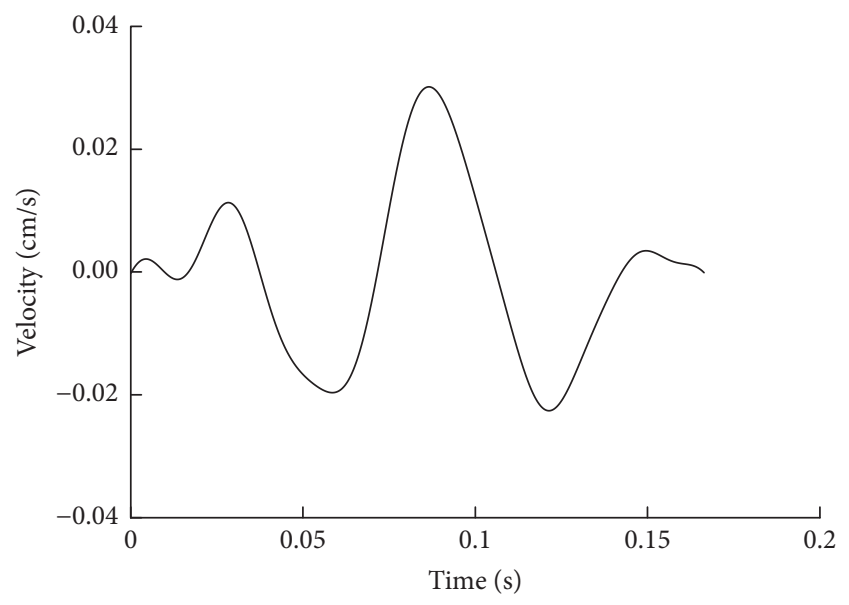

FIGURE 10: Time-history curve of input velocity load.

\subsection{Results and Analysis}

3.2.1. Dynamic Response Results of Model I. According to the point arrangement, we choose three nodes whose numbers are 5315, 86926, and 159837 at the pier foundation, center, and edge of box girder, respectively, shown in Figure 11. The locations of these nodes are the same as, or close to, the location of the monitoring points. Vibration wave curves of the typical nodes under the load of $0.03 \mathrm{~cm} / \mathrm{s}$ are presented in Figure 12.

In order to furtherly study vibration characteristics of box girder, we analyze FFT amplitude of vibration velocity under the load of $0.03 \mathrm{~cm} / \mathrm{s}$, shown in Figure 13. Vibration frequency is mainly distributed from 15 to $20 \mathrm{~Hz}$ which is consistent with the monitoring data.

PPV of typical nodes and amplification factors of box girder nodes compared with that of pier foundation are shown in Table 6.

From Table 6, we can see that when load peak is given, PPV of nodes change little with age of latest poured section. That is to say the relationship between PPV at the top of box
$\Sigma^{Y} X$

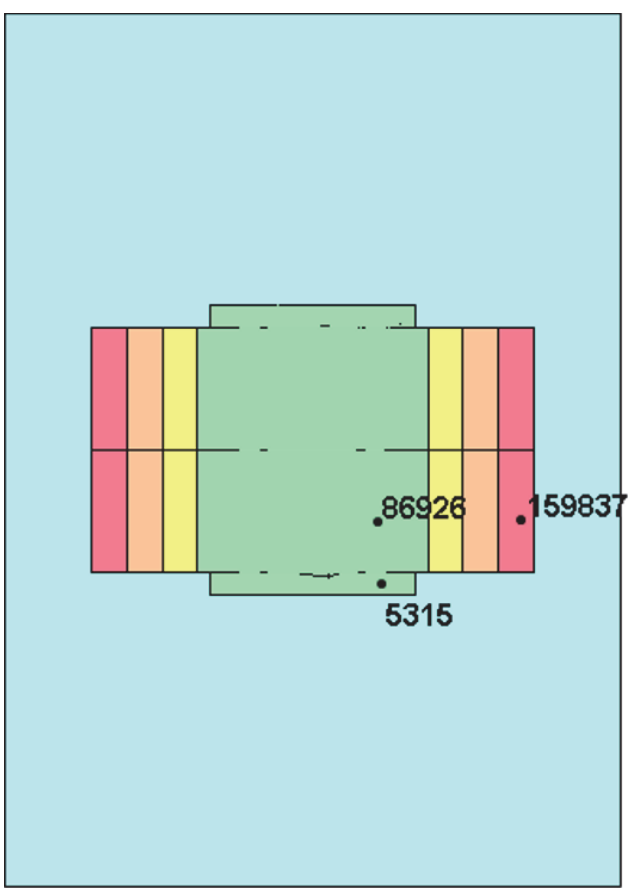

FIGURE 11: Location of typical nodes.

girder and concrete age is little when concrete is poured over 3 days. Vibration velocity at the center of box girder is 1.38 times than that of pier foundation in horizontal radial direction and 1.2 times in vertical direction. Velocity at the edge of the box girder is 3.9 times in horizontal radial direction and 2.42 times in vertical direction. Results of numerical simulation are basically consistent with field monitoring, which proves that PPV of box girder enlarges 1 to 4 times compared to pier foundation and the amplification effect is more obvious at the top edge of box girder. Vibration velocity of the box girder has 


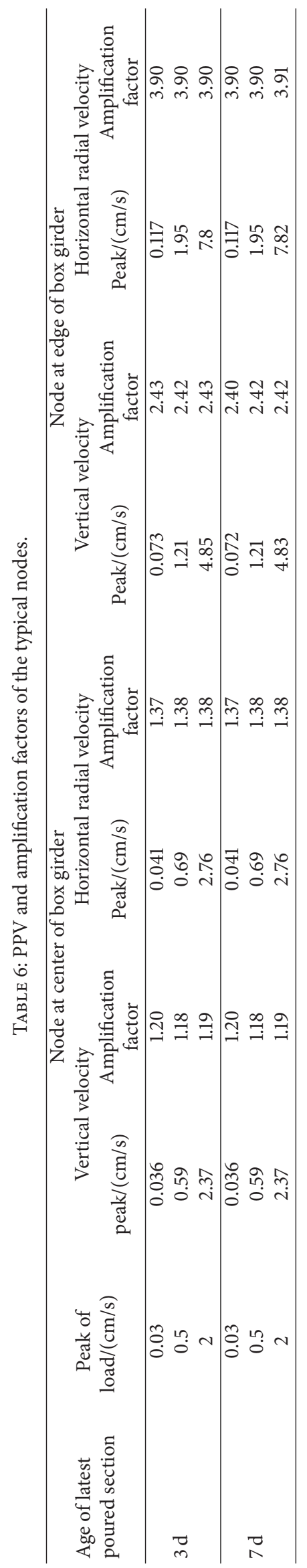




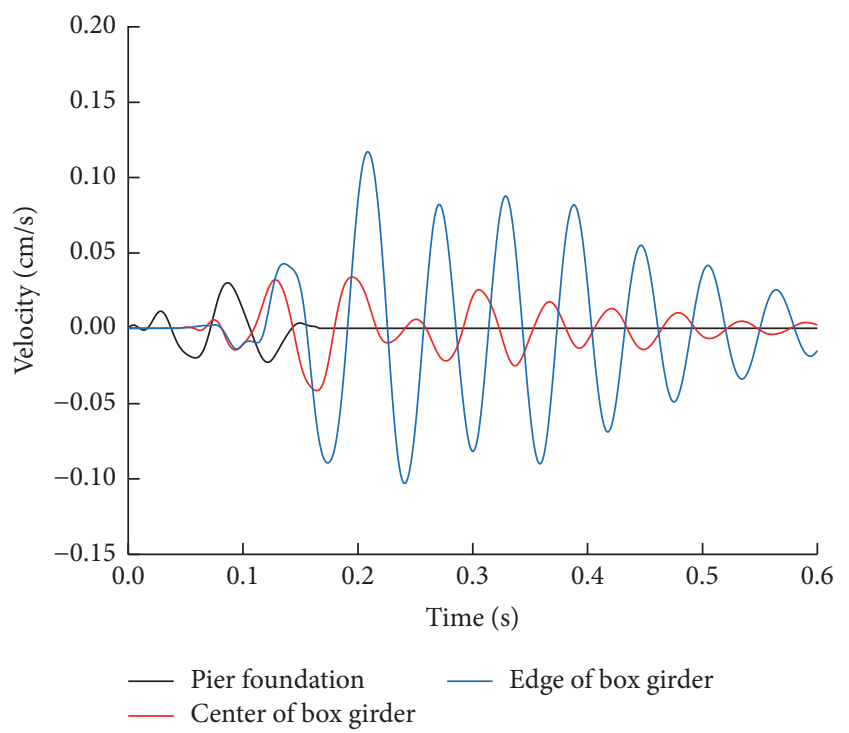

(a) Horizontal radial direction

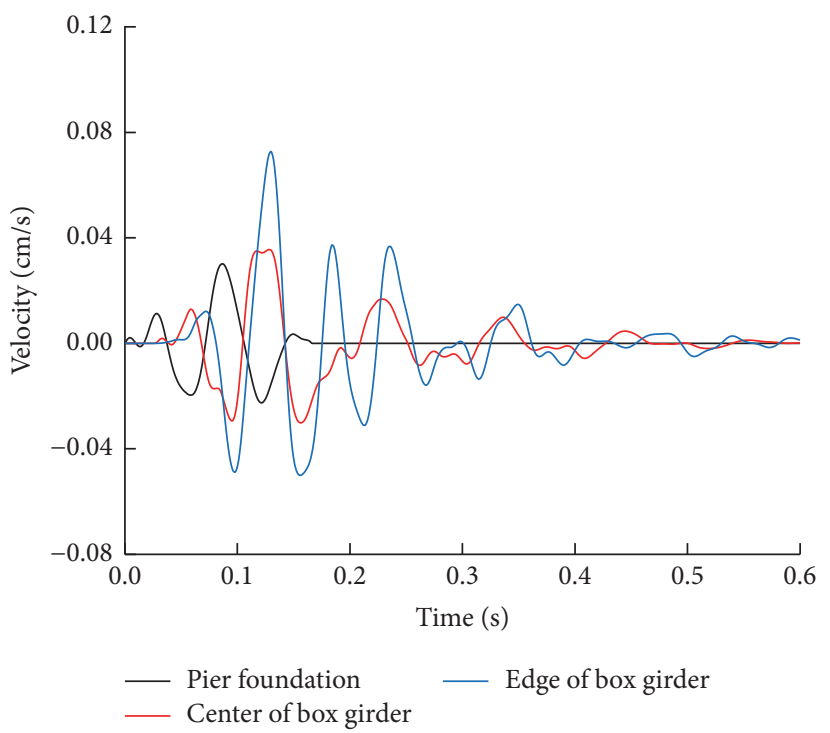

(b) Vertical direction

FIGURE 12: Vibration wave curves of the typical nodes under the load of $0.03 \mathrm{~cm} / \mathrm{s}$.

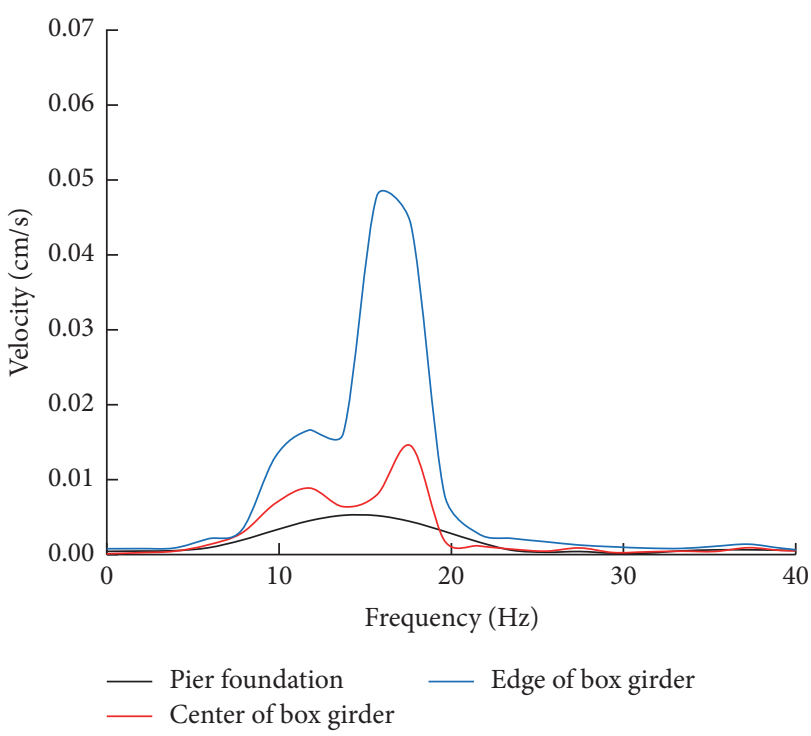

(a) Horizontal radial direction

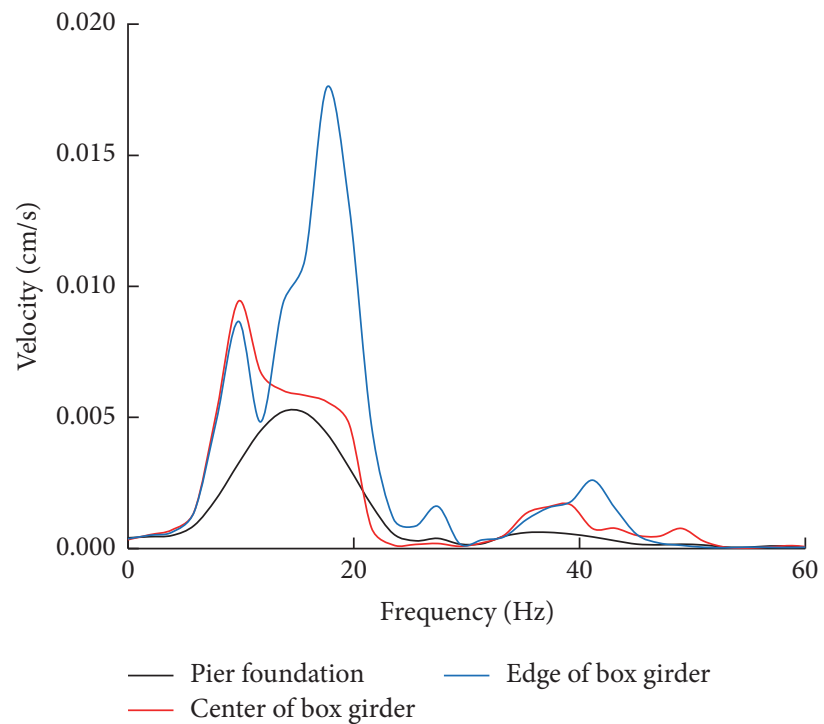

(b) Vertical direction

FIGURE 13: FFT amplitude of vibration velocity under the load of $0.03 \mathrm{~cm} / \mathrm{s}$.

an approximate linear relationship with input vibration load peak.

For furtherly exploring the damage effects of blasting vibration on the bridge and making sure the relationship between the existing crack and the blasting vibration, we analyze damage factor of the box girder under different vibration load. The main method is regarding dynamic fracture of concrete as a continuous accumulated damage process. Its fundamental point is to establish relationship between damage variable and density of microcracks in concrete and predict the damage process of concrete. We chose the KUS model here, and damage factor is defined as

$$
D=\frac{16\left(1-v^{2}\right)}{9(1-2 v)} C_{d},
$$

where $v$ is Poisson's ratio and $C_{d}$ is density of microcracks.

Under the velocity load of $0.03 \mathrm{~cm} / \mathrm{s}$, the bridge has very low vibration velocity and damage factor is approaching to 0 . Under the load of $0.5 \mathrm{~cm} / \mathrm{s}$, value of calculated maximum 

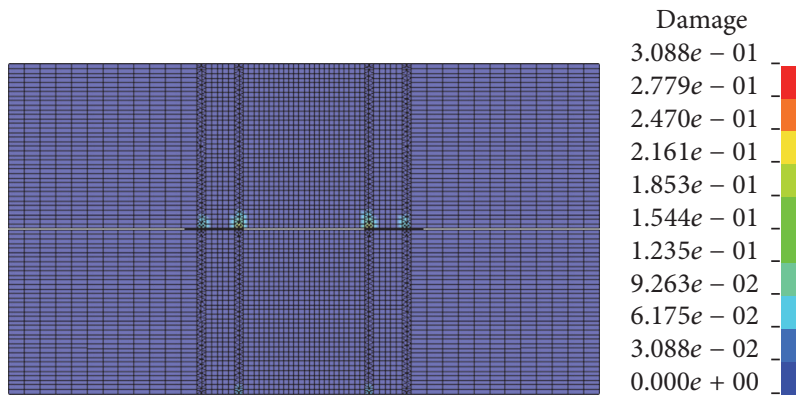

FIGURE 14: Damage area on the top of box girder under the velocity load of $2 \mathrm{~cm} / \mathrm{s}$.

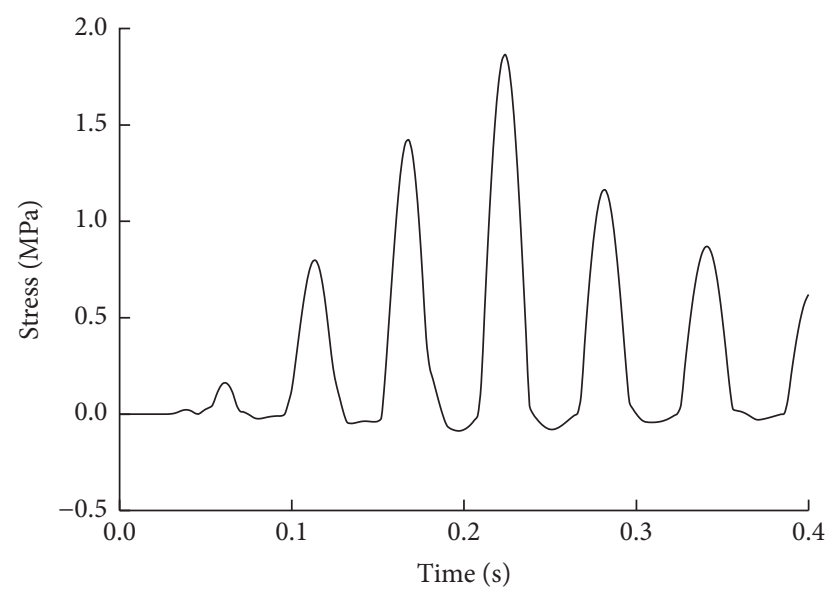

(a) First principal stress

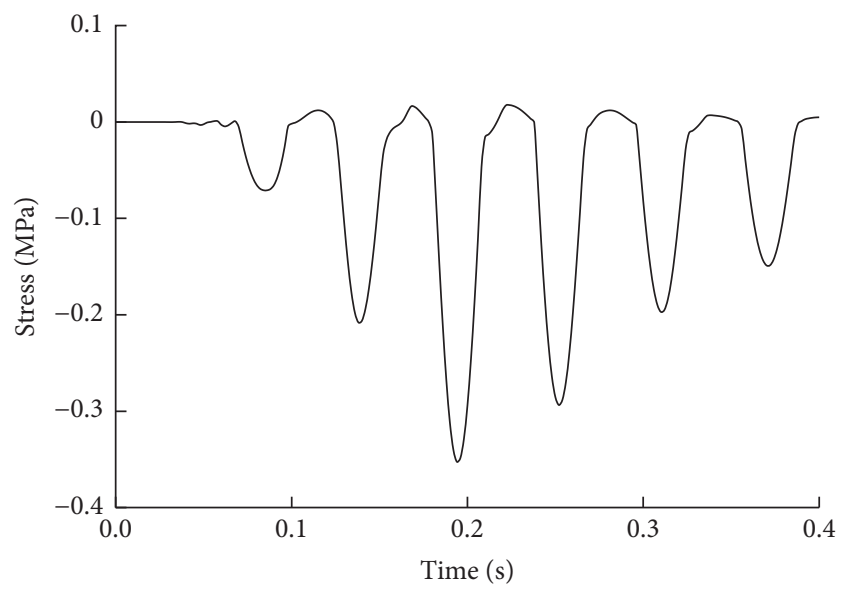

(b) Third principal stress

Figure 15: Time-history curve of principal stress at the element where maximum damage occurs.

damage is less than 0.0001 . If the velocity load is $2 \mathrm{~cm} / \mathrm{s}$, vibration velocities of nodes at top of box girder all exceed $2 \mathrm{~cm} / \mathrm{s}$ and damage factor reaches 0.31 . Damage values are shown in Table 7. We can see that, with the increase of concrete age, the strength increases but damage factor decreases. However, the influence of concrete age on damage factor of box girder is

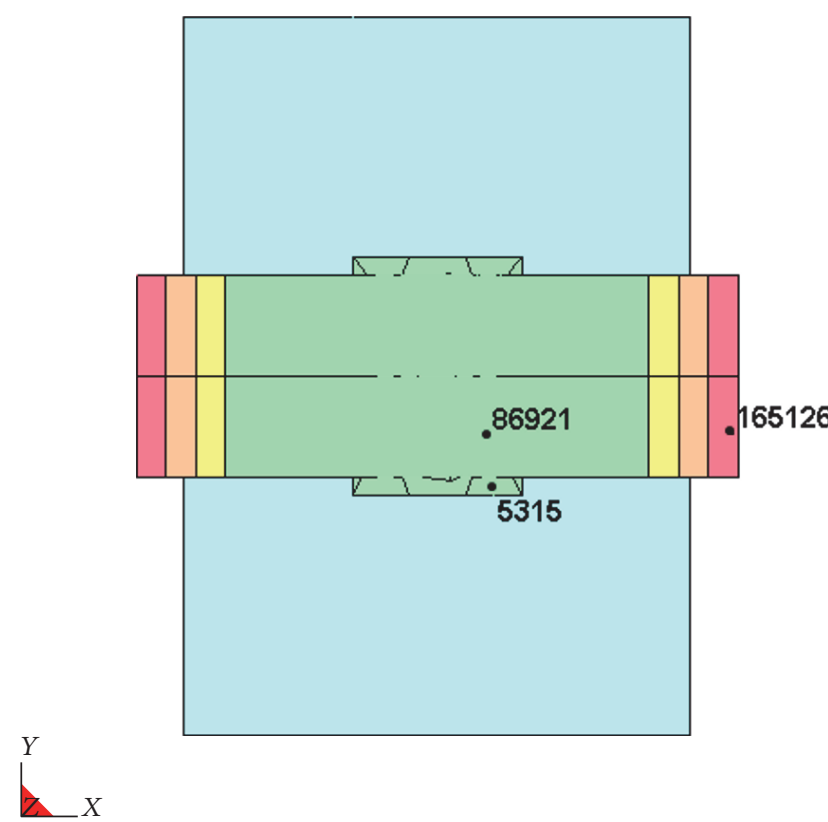

FIGURE 16: Location of typical nodes.

TABLE 7: Damage value on top of box girder under the velocity load of $2 \mathrm{~cm} / \mathrm{s}$.

\begin{tabular}{lc}
\hline Age of latest poured section & Damage value \\
\hline $3 \mathrm{~d}$ & 0.309 \\
$7 \mathrm{~d}$ & 0.299 \\
$28 \mathrm{~d}$ & 0.287 \\
\hline
\end{tabular}

limited when concrete is poured over 3 days. Figure 14 shows damage area generated on the top of box girder; damage occurs at center of the box girder where two half bridges contact. Figure 15 shows time-history curve of the first and third principal stress at the element where maximum damage occurs. The maximum absolute value of first principal stress is $1.86 \mathrm{MPa}$ and that of the third principal stress is $0.36 \mathrm{MPa}$. Tensile and compressive stresses are smaller than tensile and compressive strength of concrete. We have not found plastic zone in the numerical simulation. So vibration generated by velocity load such as $2 \mathrm{~cm} / \mathrm{s}$ could not lead to visible cracks on the box girder. Cracks appearing on the new poured box girder shown in Figure 3 should be caused by other reasons.

3.2.2. Dynamic Response of Model II. We choose three nodes at the pier foundation, center, and edge of box girder, whose numbers are 5315, 86921, and 165126, respectively, as shown in Figure 16. From the above, we know that the effect of concrete age on dynamic response and damage of box girder is limited, so we only choose the condition that the latest poured section age is 3 days to simulate. Vibration velocities and amplification factors of typical nodes under different load are shown in Table 8.

Blasting vibration velocity at the center of the box girder is 2.46 times than that of pier foundation in horizontal radial 


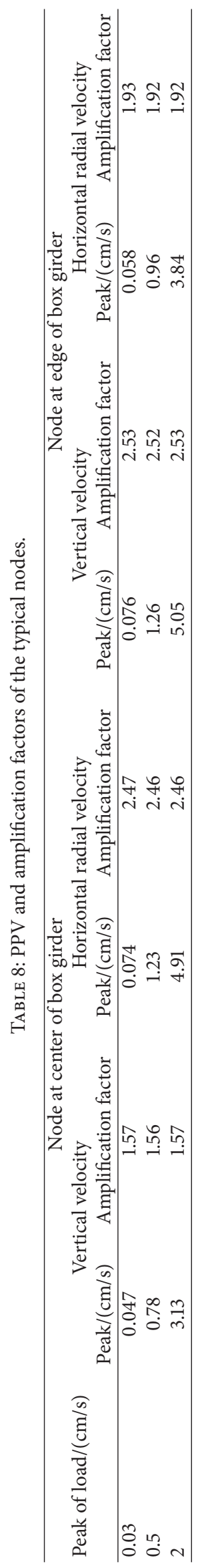






(a) Horizontal radial direction

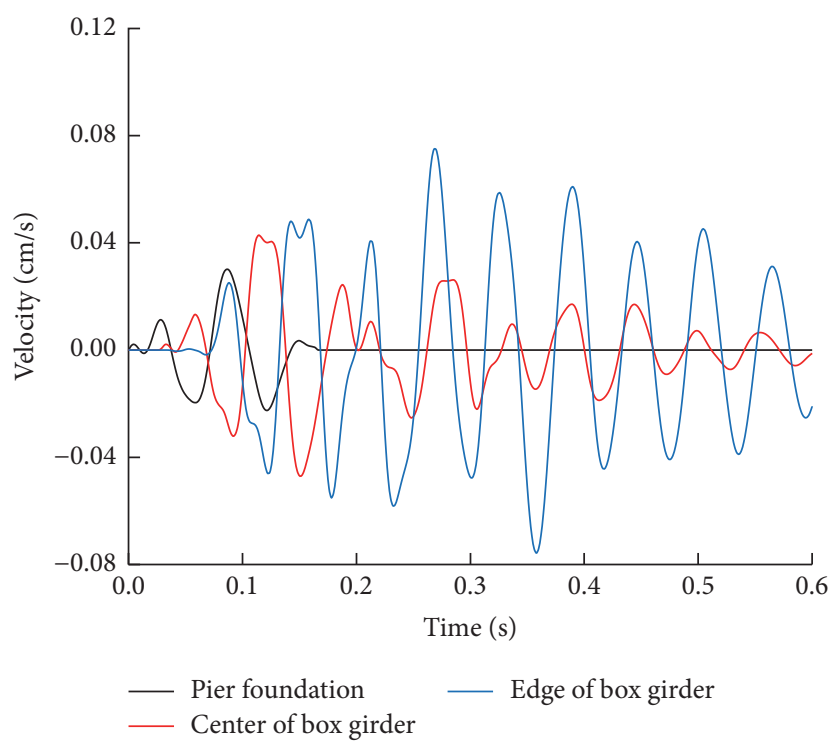

(b) Vertical direction

FIGURE 17: Vibration wave curves of the typical nodes under the load of $0.03 \mathrm{~cm} / \mathrm{s}$.

direction and 1.56 times in vertical direction while velocity at the edge is 1.93 times in horizontal radial direction and 2.53 times in vertical direction. Compared with PPV amplification factors of model I and the field monitoring data, the results of numerical simulation well match the monitored results; that is, the amplification factor of the edge in vertical direction increases but decreases in horizontal radial direction with the extension of cantilever casting section. We also get that amplification factors of the center in both directions are larger as the section gets longer. Vibration velocity wave with peak velocity load of $0.03 \mathrm{~cm} / \mathrm{s}$ is shown in Figure 17. Compared with Figure 12, the vertical vibration wave attenuates slower and vibration duration that extends significantly with the section extending.
After analyzing FFT amplitude of vibration velocity with the load of $0.03 \mathrm{~cm} / \mathrm{s}$, we find that vibration frequency is mainly distributed from 10 to $20 \mathrm{~Hz}$. It is consistent with the monitored results.

Damage factor increases to 0.32 under the load of $2 \mathrm{~cm} / \mathrm{s}$. The maximum of first principal stress at the position where damage is larger is $1.92 \mathrm{MPa}$ while the maximum absolute value of third principal stress is $0.38 \mathrm{MPa}$. Tensile and compressive stresses are, respectively, smaller than tensile and compressive strength of concrete. We have not found plastic zone in the numerical simulation. So blasting vibration could not lead to visible cracks on the box girder.

\section{Conclusion}

Based on monitoring and analysis of blasting vibration for Yesanhe Super Large Bridge in construction, we conduct a numerical simulation about dynamic response of the bridge under blasting seismic and obtain the following conclusions:

(1) Blasting excavation at Yesanhe Hydropower Station does intrude vibration response of Yesanhe Super Large Bridge. Under the condition that maximum tolerant explosive quantity of single shot is $141 \mathrm{~kg}$ and the distance is 450 meters, PPV of the bridge is very low. Monitoring data and numerical simulation both show that PPV of box girder enlarges 1 to 4 times than that of pier foundation.

(2) With the extension of cantilever casting section of the box girder, the vibration amplification factor at the edge in vertical direction increases but decreases in horizontal radial direction; amplification factor at the center in both directions increases, so does the duration of vertical vibration. However, the relationship between PPV of box girder and concrete age is little when concrete is poured over 3 days.

(3) In the simulation, vibration velocity of the box girder has an approximately linear relationship with the input load. When the velocity load is less than $0.5 \mathrm{~cm} / \mathrm{s}$, damage does not appear on the bridge; when it comes to $2 \mathrm{~cm} / \mathrm{s}$, the maximum damage factor at top of box girder is about 0.3. The maximum tensile and compressive stresses are less than tensile and compressive strength of concrete, respectively. Blasting vibration is not a threat to the safety of the bridge. So we can conclude that cracks appearing on the new poured box girder should be caused by other reasons.

\section{Competing Interests}

The authors declare that there is no conflict of interests regarding the publication of this paper.

\section{Acknowledgments}

This work is supported by National Natural Science Foundation of China (nos. 51279146 and 51479147), Program for New 
Century Excellent Talents in University (NCET-12-0425). The authors sincerely express their thanks to all supports.

\section{References}

[1] T. D. Northwood, "Blasting vibrations and building damage," Engineering, vol. 215, pp. 973-978, 1963.

[2] G. W. Ma, H. Hao, and Y. X. Zhou, "Assessment of structure damage to blasting induced ground motions," Engineering Structures, vol. 22, no. 10, pp. 1378-1389, 2000.

[3] N. Yugo and W. Shin, "Analysis of blasting damage in adjacent mining excavations," Journal of Rock Mechanics and Geotechnical Engineering, vol. 7, no. 3, pp. 282-290, 2015.

[4] I.-S. Ha, "Estimation of shear wave velocity of earth dam materials using artificial blasting test," Soil Dynamics and Earthquake Engineering, vol. 55, pp. 120-129, 2013.

[5] S.-L. Li, D.-S. Liu, Y.-W. Cui, and H.-Y. Zhao, "Research on the dynamic effect of long-span railway bridge pier based on real blasting seismic waves," Transaction of Beijing Institute of Technology, vol. 35, no. 2, pp. 123-143, 2015.

[6] F. W. Huang, D. Y. Liu, H. Luo, and B. Liu, "Analysis on attenuation-amplification effect and vibration monitoring of pier-beam of continuous beam bridge under near blasting," Applied Mechanics and Materials, vol. 353-354, pp. 1919-1922, 2013.

[7] A. Bayraktar, A. C. Altunişik, and M. Özcan, "Safety assessment of structures for near-field blast-induced ground excitations using operational modal analysis," Soil Dynamics and Earthquake Engineering, vol. 39, pp. 23-36, 2012.

[8] A. Bayraktar, T. Türker, A. Can Altunişik, and B. Sevim, "Evaluation of blast effects on reinforced concrete buildings considering operational modal analysis results," Soil Dynamics and Earthquake Engineering, vol. 30, no. 5, pp. 310-319, 2010.

[9] R. P. Dhakal and T.-C. Pan, "Response characteristics of structures subjected to blasting-induced ground motion," International Journal of Impact Engineering, vol. 28, no. 8, pp. 813-828, 2003.

[10] B. Li, H.-C. Rong, and T.-C. Pan, "Drift-controlled design of reinforced concrete frame structures under distant blast conditions-Part I: theoretical basis," International Journal of Impact Engineering, vol. 34, no. 4, pp. 743-754, 2007.

[11] B. Li, H.-C. Rong, and T.-C. Pan, "Drift-controlled design of reinforced concrete frame structures under distant blast conditions-Part II: implementation and evaluation," International Journal of Impact Engineering, vol. 34, no. 4, pp. 755-770, 2007.

[12] X. S. Huo and L. U. Wong, "Experimental study of early-age behavior of high performance concrete deck slabs under different curing methods," Construction and Building Materials, vol. 20, no. 10, pp. 1049-1056, 2006.

[13] Y.-S. Wang, J.-H. Huang, J.-H. Li, and Y.-F. Yang, "Early-stage strength growth of high-strength concrete in outer freezing shaft walls," Journal of China University of Mining and Technology, vol. 37, no. 5, pp. 595-599, 2008.

[14] W.-B. Lu, Y. Luo, M. Chen, and D.-Q. Shu, "An introduction to Chinese safety regulations for blasting vibration," Environmental Earth Sciences, vol. 67, no. 7, pp. 1951-1959, 2012.

[15] M. Chen, W. Lu, and C. Yi, "Blasting vibration criterion for a rock-anchored beam in an underground powerhouse," Tunnelling and Underground Space Technology, vol. 22, no. 1, pp. 69-79, 2007.
[16] D. Yáñez, "Blast control for El Cajón a hydroelectric project in Nayarit, Mexico," Journal of Explosives Engineering, vol. 23, no. 3, pp. 34-41, 2006.

[17] Z.-G. Zhao, J.-H. Yang, W.-B. Lu, P. Yan, and M. Chen, "Selection of spraying time for permanent shotcrete in deepburied tunnels based on evaluation of the influence of blasting vibration," Journal of Vibration and Shock, vol. 34, no. 7, pp. 8-14, 2015.

[18] P.-Y. Yan and Q. Cui, "Effects of curing regimes on strength development of high-strength concrete," Journal of the Chinese Ceramic Society, vol. 43, no. 2, pp. 133-137, 2015.

[19] M. Sidney, J. Francis, and D. David, Concrete, translated by K. R. Wu, Chemical Industry Press, Beijing, China, 2005.

[20] D. C. Zhou, Z. C. Dong, and L. Wang, "Equivalent linearization model research based on performance in seismic design," Journal of Earthquake Engineering and Engineering Vibration, vol. 33, no. 3, pp. 110-117, 2013. 


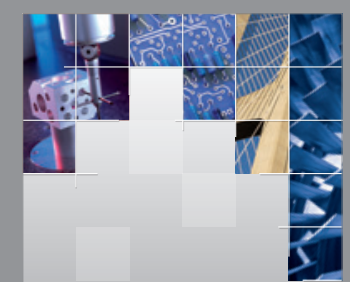

\section{Enfincering}
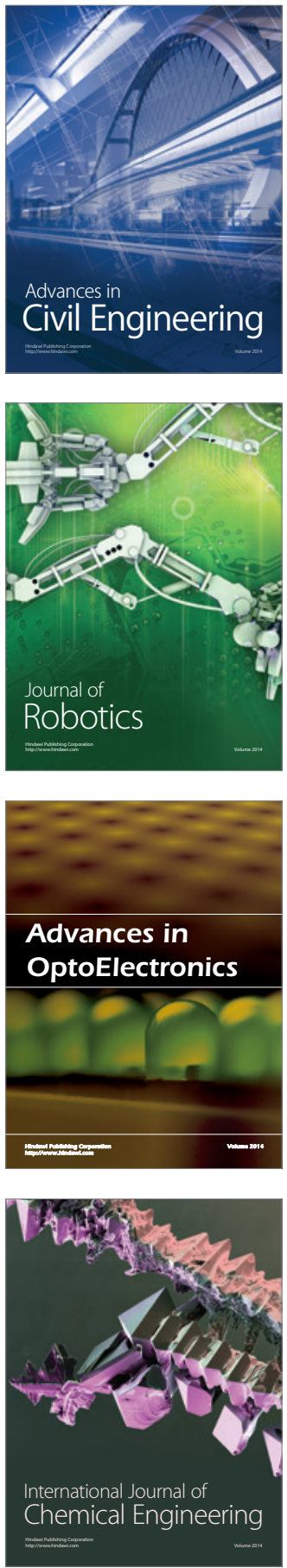

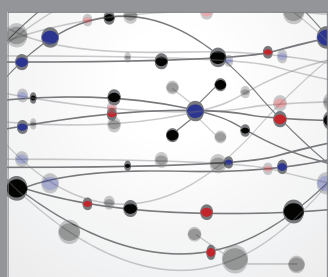

The Scientific World Journal

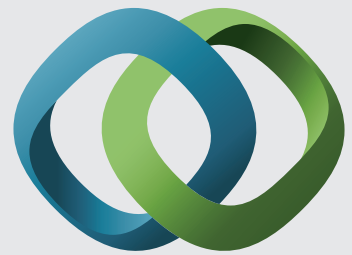

\section{Hindawi}

Submit your manuscripts at

https://www.hindawi.com
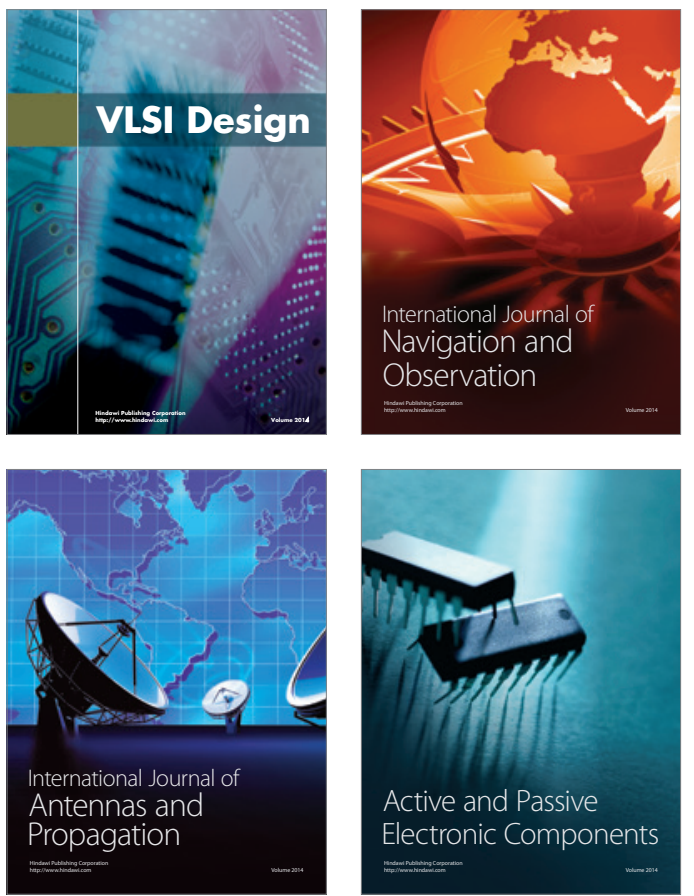
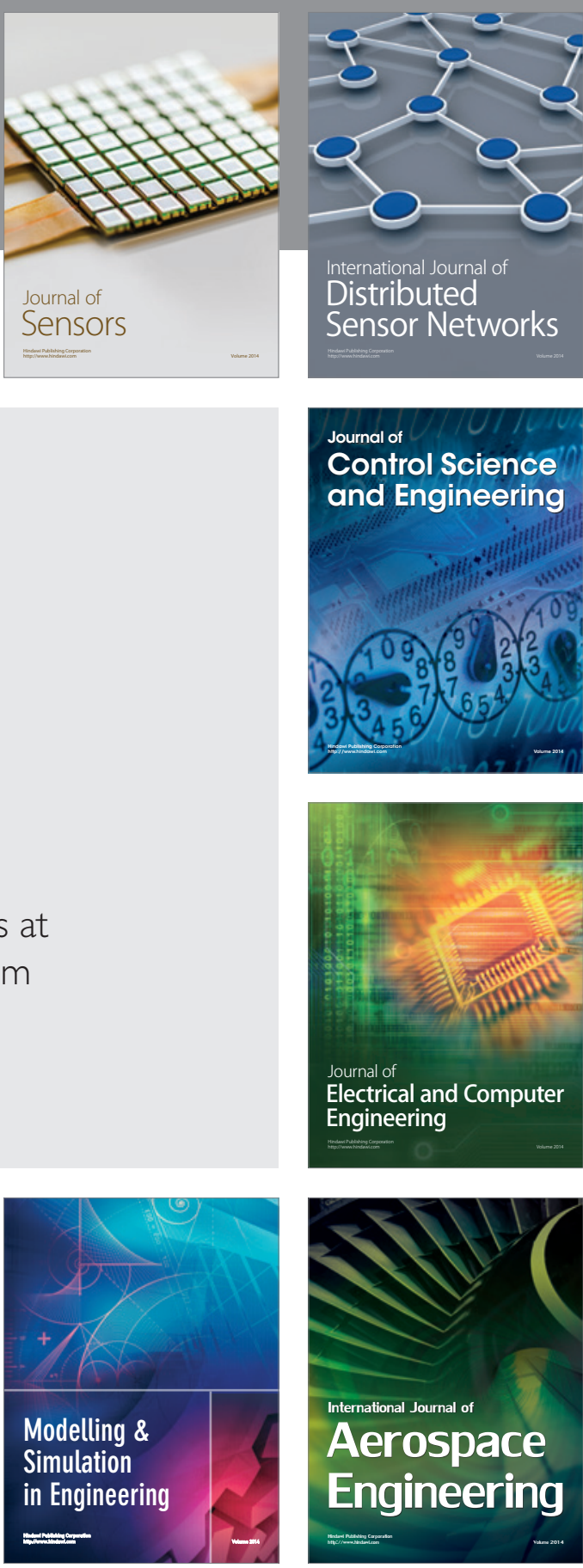

International Journal of

Distributed

Sensor Networks

$-$

Joumal of

Control Science

and Engineering
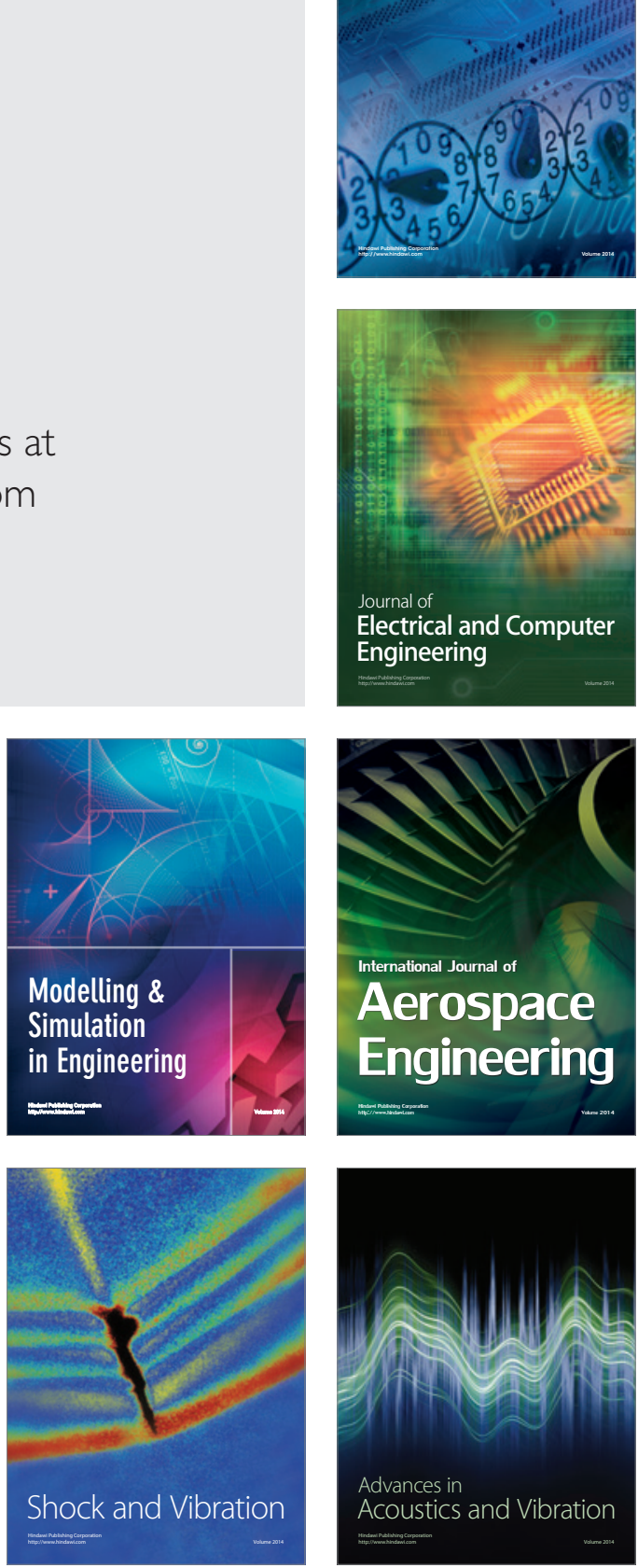